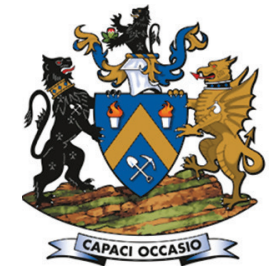

Affiliation:

${ }^{1}$ Council for Scientific and Industrial Research (CSIR), Pretoria, South Africa.

Correspondence to:

S. Khan

Email:

skhan2@csir.co.za

\section{Dates:}

Received: 30 Apr. 2020

Revised: 9 Oct. 2020

Accepted: 18 Nov. 2020

Published: January 2021

\section{How to cite:}

Mpofu, M., Ngobese, S.,

Maphalala, B., Roberts, D., and

Khan, S. 2021

The influence of stemming

practice on ground vibration and

air blast.

Journal of the Southern African

Institute of Mining and Metallurgy,

vol. 121, no. 1, pp. 1-10.

\section{DOI ID:}

http://dx.doi.org/10.17159/24119717/1204/2021

ORCID

M. Mpofu

https://orcid.org/0000-0003-

2010-7596

S. Khan

https://orcid.org/0000-0002-

6362-5361

\title{
The influence of stemming practice on ground vibration and air blast
}

\author{
M. Mpofu' ${ }^{1}$, S. Ngobese' ${ }^{1}$ B. Maphalala1', D. Roberts' ${ }^{1}$, and S. Khan ${ }^{1}$
}

\begin{abstract}
Synopsis
This paper details an assessment of stemming practices at a South African opencast coal mine and their influence on ground vibration and air blast. Quantitative and qualitative analysis methods were used for the study. The parameters assessed for the quantitative analyses included stemming length, stemming material type, blast-hole depth, burden, and spacing. Pre-blast data from the mine was analysed to determine the deviation between actual and mine design stemming parameters. Mine design stemming length was also compared to the rule-of-thumb stemming lengths. Peak particle velocity (ground vibration) and air blast data from seismograph stations around the mine was analysed to determine the correlation between stemming length and excessive ground vibration and air blast. The qualitative analysis involved observations of blasting procedures at the mine to determine compliance with mine procedures. Some level of non-compliance of actual stemming parameters to design stemming parameters was found, which initially suggested that non-compliance may have contributed to excessive air blast. However, further analysis of the seismograph results indicated no direct correlation between stemming length and excessive air blast and ground vibration. Since stemming parameters are interrelated, it is crucial that all blasting procedures, including stemming, are executed in accordance with best practice, and recorded accurately. There is a need for digital systems for capturing on-bench blasting parameters, as the currently used manual data recording and reporting systems are inefficient and prone to error. Improvements to blast designs are possible through efficient and accurate data recording and reporting systems.
\end{abstract}

\section{Keywords}

opencast mining, blasting, stemming, ground vibration, air blast.

\section{Introduction}

Rock blasting using explosive energy is an integral part of the mining process. However, poor blasting from inefficient blast designs and practices may result in adverse impacts on the environment, infrastructure, and the health and safety of people and wildlife in surrounding communities. Some of the negative impacts of inefficient blasting include excessive ground vibrations, air blast, flyrock, noise, and blasting fumes. Potential causes of these effects include, but are not limited to (Bajpayee, Verakis, and Lobb, 2004; Mohamed, Armaghani, and Motaghedi, 2013):

i. Undercharging or overcharging blast-holes

ii. Overly confined or inadequately confined blast-holes

iii. Inappropriate timing sequence

iv. Unfavourable geological and geotechnical conditions.

A team of researchers at the Council for Scientific and Industrial Research (CSIR) undertook a project for Coaltech on 'Monitoring of Blasting and Determination of Optimal Stemming' in 2018. This paper forms part of the research work that was done to assess stemming practices at a South African opencast coal mine and the influence of stemming practices on ground vibration and air blast at the mine. The hypothesis was that excessive ground vibration and air blast are a result of incorrect stemming design and practice. 'Incorrect stemming design and practice' in this context refers to non-compliance of actual stemming parameters with mine design parameters.

The paper highlights the design guidelines for stemming parameters (length and material type), compares the actual stemming parameters to mine design stemming parameters (stemming length, burden, spacing, and hole depth) at the mine; qualitatively assesses the compliance with standard operating blasting procedures; and discusses the relationship between stemming practices, air blast, and ground vibration at the mine. 


\section{The influence of stemming practice on ground vibration and air blast}

\section{Background}

\section{Study site}

The study was conducted at an opencast mine located in the Mpumalanga Province of South Africa, in the Witbank Coalfield. The Witbank Coalfield has five mineable bituminous coal seams numbered consecutively from the oldest (No.1 Seam) to the youngest (No. 5 Seam) (Banks et al., 2011). The Witbank Coalfield contains a large and important resource of high-yield, export quality coal (especially in the No. 4 Seam), and an estimated $50 \%$ of South Africa's recoverable coal reserves (Banks et al., 2011).

The mine geology consists of alternating layers of sandstone, shale, and coal seams. The No. 2, 3, 4, and 5 seams are mined by opencast methods.

\section{The importance of stemming in relation to ground vibration and air blast}

Stemming involves placing an inert material on top of explosives in a blast-hole (NPS, 1999; de Graaf, 2013). The stemming material may include drill chippings, gravel, or sand. Stemming enables the efficient use of energy for rock breakage and prevents the escape of gases when explosives are detonated (Boshoff and Webber-Youngman, 2011). Appropriate stemming material also protects the loaded explosives from accidental detonation and aids in the generation of a loose muckpile that is easy to load (NPS, 1999). The premature ejection of stemming material results in the loss of explosive energy and the rapid venting of gases to the atmosphere. This leads to air blast, a shock wave that results from the detonation of explosives, which is usually accompanied by violently ejected flyrock (de Graaf, 2013). Poor stemming practices also contribute to poor fragmentation, surface overbreak, bad heave or rock displacement, and excessive noise and ground vibration that affect the surrounding environment (Sereme et al., 2019). Overconfinement can result in excessive ground vibration, especially when excessive subdrilling is practiced or larger than recommended burdens are used. Unconfined or inadequately confined blast-holes cause air blast, suggesting that the appropriate stemming length and material type is an important factor to consider in blasting practices (de Graaf, 2013).

Aspects to consider in stemming design are stemming length, material type, and stemming-related parameters such as burden, spacing, and hole depth. The stemming length is dependent on various factors that include the power of the explosives, blasthole diameter, burden, spacing, stemming material, and the surrounding rock properties (Neale, 2010; de Graaf, 2013).

\section{Stemming length}

Generally, stemming parameters are designed for each mine based on the unique geology and varying conditions such as material thickness (Neale, 2010). The stemming length adopted by the mine investigated, as shown in Equation [1] (NPS, 1999; de Graaf, 2013; Lusk and Worsey, 2013), is based on best practice guidelines.

$$
T=20 \times D
$$

where: $T=$ stemming length $(\mathrm{m})$ and $D=$ blast-hole diameter $(\mathrm{m})$.

A different rule-of-thumb recommends that the stemming length should fall within the range shown in Equation [2] (NPS, 1999; de Graaf, 2013; Lusk and Worsey, 2013).

$$
T=0.7 \mathrm{~b} \text { to } 1.2 \mathrm{~b}
$$

where: $T=$ stemming length $(\mathrm{m})$ and $b=$ burden $(\mathrm{m})$.

Generally, stemming lengths shorter than $0.7 \mathrm{~b}$ result in air blast, flyrock, noise, and overbreak (Lusk and Worsey, 2013).

\section{Stemming material}

A stemming material should have high shear strength and high density to improve the effectiveness of a blast (BME, 2018). Furthermore, stemming material should be of such a size and shape that the fragments achieve good interlocking.

According to Lusk and Worsey (2013), the following basic guideline is applied to stemming material (Equation [3]):

$$
\text { Stemming material size }=\frac{1}{8} \times D
$$

Generally, the stemming material type is selected based on availability at the mine. According to Patidar (2017), sand, fly ash, and clay are commonly found at surface coal mines and may be used separately or mixed to improve stemming efficiency. Drill chippings, the fine material generated by drilling of blastholes, are a readily available type of stemming material. Drill chippings may be used wet or dry, with the wet chippings being less effective than dry chippings due to reduced interlocking ability (BME, 2018). Crushed stone or aggregate is another cost-effective type of stemming material that can be produced at the site to a desirable size (de Graaf, 2013). An alternative to aggregate is chrome slag, which is the waste material from the production of ferrochrome. Its physical and mechanical qualities make it a suitable replacement for natural aggregate as stemming material (Moodie, 2016). One of the benefits of using chrome slag is that it is otherwise considered as waste material, therefore its use eliminates the cost and issues associated with discarding it. The choice between natural aggregate and chrome slag depends on stemming material size, availability, and associated costs.

Stemming accessories used in conjunction with stemming materials and which are commercially available include concrete plugs, stemming plugs, Rocklock plugs, tulip plugs, and foam plugs (Karakus et al., 2003; Cevizci, 2012).

\section{Stemming-related parameters (burden, spacing, blast- hole depth)}

An assessment of stemming practice could not have been done in isolation. Other parameters that affect blast results are closely linked to stemming practice. Burden, spacing, and blast-hole length (depth) are some of the interrelated parameters, critical during drilling, which were assessed for this study (de Graaf, 2013). The other interrelated parameters are hole diameter, bench height, subdrill, and drilling patterns (NPS, 1999; Lusk \& Worsey, 2013). Due to the complex nature of blast design, it was not possible to evaluate all the parameters mentioned. This may constitute a limitation of the study. The parameters assessed were those for which data was readily available and which were critical for the research project.

Sereme et al. (2019) defined spacing as the distance between adjacent blast-holes, measured perpendicular to the burden. Spacing is generally measured between holes positioned parallel to the cut face of the bench. The relationship for burden and spacing is a ratio of 1.0 to 1.5 . Burdens that are too large produce inadequate fragmentation, toe problems, and excessive ground vibrations (NPS, 1999; Lusk \& Worsey, 2013; de Graaf, 2013). 


\section{The influence of stemming practice on ground vibration and air blast}

The hole length is a function of the bench height and the subdrill combined. The subdrill is the distance drilled below the floor level to ensure that the full face of the rock is removed. Hole depths that are less than 1.5 times the burden cause excessive air blast and flyrock (NPS, 1999; Lusk \& Worsey, 2013; de Graaf, 2013).

\section{Methodology}

The stemming practices at the mine were assessed using quantitative and qualitative methods. The tasks included the collation of stemming parameters; analyses and comparisons of the stemming parameter (mine design $v s$. actual $v S$. rule-ofthumb) values; collation and analyses of data indicating the performance of the blasts (ground vibration and air blast); and finally a monitoring exercise to determine compliance of the mine blasting practices with their standard operating procedures.

\section{Quantitative analysis}

The quantitative analysis included the collation and scrutiny of pre-blast and post-blast data. Pre-blast reports, blast-hole data sheets, and the stemming design guidelines were obtained from the mine to conduct the pre-blast quantitative analysis. The stemming parameters assessed were stemming length, stemming material, and stemming-related parameters that included burden, spacing, and hole depth.

Data on coal (No. 2 and No.4 seams), shale, sandstone, and interburden (mixture of sandstone and torbanite) blasts was assessed. The majority of the available data was from blasts prior to the researchers' presence at the study area.

Some of the challenges encountered during the collation of data from the pre-blast reports included the need for reorganization of reports in chronological order; illegibility and data capturing errors; incomplete fields of data; and the need to scan the hardcopy reports. These challenges necessitated re-capturing of the data on a spreadsheet to facilitate ease of interpretation and analysis of the data.

The actual stemming lengths recorded in the pre-blast reports were compared against the recommended mine design stemming lengths to determine their level of compliance. A total of 70 blasts ( 25 coal, 17 interburden, 16 shale, and 12 sandstone) were analysed. Thereafter, the stemming length variations for actual, mine design, and rule-of-thumb (Equation [1]) stemming lengths were analysed for coal, interburden, shale, and sandstone. Based on the results, the researchers deemed it necessary to further analyse how the design stemming length varied with the rule-ofthumb (Equation [2]).
The post-blast analysis was conducted by assessing fourteen months of data from eight seismograph stations around the mine that record peak particle velocity (PPV ground vibration) and air blast. The seismographs measure data continuously and trigger only when a pre-set threshold value is exceeded. The threshold values set by the mine for ground vibration and air blast were guided by the international US Bureau of Mines (USBM) standards. According to Sereme et al., (2019) these values were below the threshold of $134 \mathrm{~dB}$ typically set for South African coal mines. The ground vibration threshold limits set by the mine were such that $95 \%$ of all blasts should be below $130 \mathrm{~dB}$ and $85 \%$ below $125 \mathrm{~dB}$. The air blast threshold limits set by the mine were such that $95 \%$ of all blasts should be below $2 \mathrm{~mm} / \mathrm{s}$ and $85 \%$ below $1 \mathrm{~mm} / \mathrm{s}$.

The pre-blast data and post-blast results were examined and plotted graphically to determine if there was a correlation between stemming length compliancy and air blast or ground vibration.

\section{Qualitative analysis}

The qualitative analysis was aimed at monitoring stemming practice and compliance with mine standards and procedures (Sereme et al., 2019). The researchers observed the drilling, charging, and blasting procedures at three mining blocks for three consecutive weeks. Data gathered during the observations included the blast location, bench material, hole condition, detonator type, stemming parameters, and comments on the observations. Measurements of newly drilled holes, while the researchers were at the mine, were done by the drill-and-blast team, closely observed by the researchers.

\section{Results and discussion}

\section{Quantitative analysis}

\section{Stemming length}

Figure 1 illustrates the general relationship between the actual stemming lengths and the mine design stemming lengths for all the blasts.

The sandstone blasts show the greatest variation in stemming length compared to coal, interburden, and shale. Deviations of the actual stemming length from the design for coal, interburden, shale, and sandstone are quantified in Figures 2-5.

As shown in Figure 2 the actual stemming length used on the mining block differed from the design stemming length for all the 25 coal blasts investigated. Blasts 1 to 12 were No. 2 Seam coal, while blast 13 to 25 were on No. 4 Seam coal. There was also a variation between the rule-of-thumb stemming length (20D) and the design stemming length.

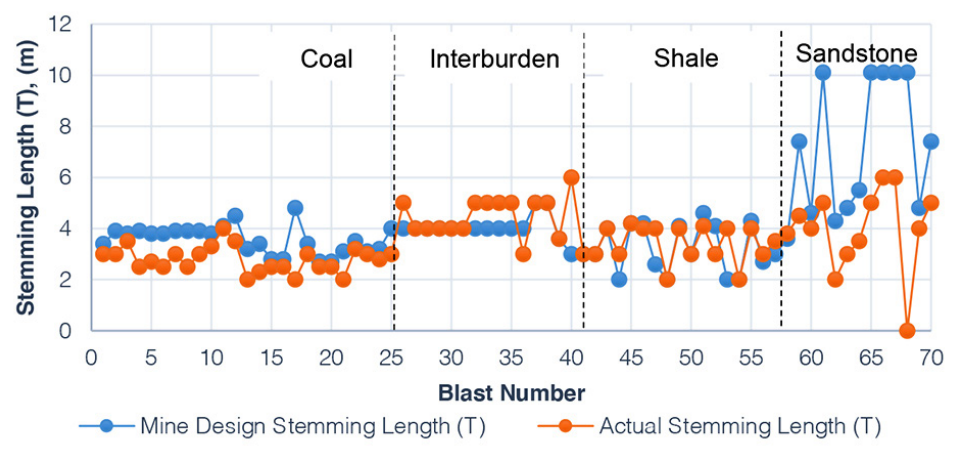

Figure 1-A comparison of mine design and actual stemming lengths for all blasts 


\section{The influence of stemming practice on ground vibration and air blast}

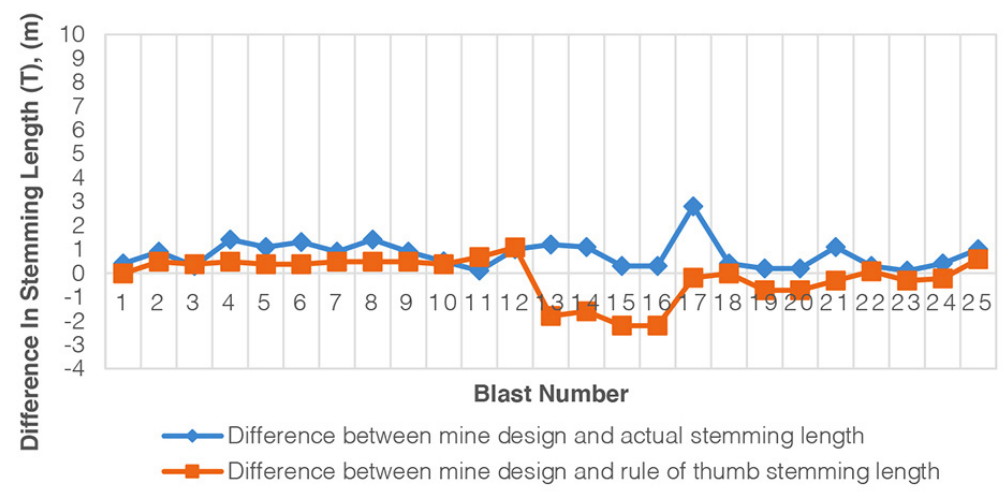

Figure 2-Stemming length variations for coal blasts

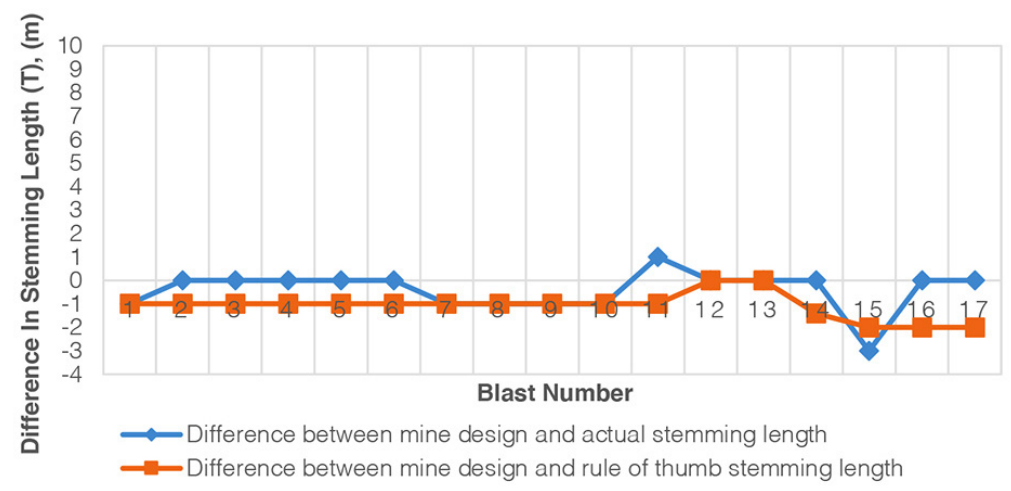

Figure 3-Stemming length variations for interburden

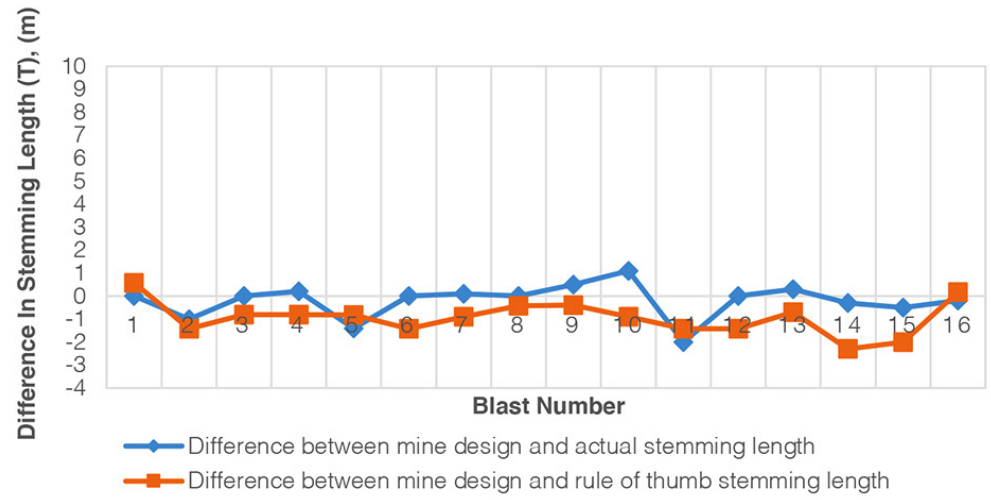

Figure 4-Stemming length variations for shale blasts

The mine design stemming length was greater than the actual stemming length for all the analysed coal blasts, as shown by the positive differences in Figure 2. The average and maximum differences were $0.78 \mathrm{~m}$ and $2.8 \mathrm{~m}$ (blast 17 ), respectively. Hole diameters for blasts 1 to 12 and blasts 18 to 25 were $171 \mathrm{~mm}$, while those for blasts 13 to 17 were $250 \mathrm{~mm}$. This equated to rule-of-thumb stemming lengths of $3.42 \mathrm{~m}$ and $5.0 \mathrm{~m}$ for $171 \mathrm{~mm}$ and $250 \mathrm{~mm}$ diameter holes, respectively. The variation between mine design and rule-of-thumb stemming lengths was less than $0.5 \mathrm{~m}$ for the first eleven blasts. The mine design stemming length was less than the rule-of-thumb values in thirteen blasts. The average difference between mine design and rule-of-thumb stemming length was $0.67 \mathrm{~m}$, with a maximum difference of $2.20 \mathrm{~m}$ (blast 16).

More than half (10 out of 17) of the interburden blasts showed compliance between the design stemming length and the actual stemming length. The design stemming length exceeded the actual stemming length by $1.0 \mathrm{~m}$ for blast 11 and was $3.0 \mathrm{~m}$ less than the actual stemming length for blast 15 (Figure 3).

The design stemming length was less than or equal to the rule-of-thumb stemming length for all the interburden blasts, with an average difference of $1.0 \mathrm{~m}$. Hole diameters were designed at $250 \mathrm{~mm}$, which corresponds to a rule-of-thumb stemming length of $5.0 \mathrm{~m}$. The maximum difference between the mine design and rule-of-thumb stemming length was $2.0 \mathrm{~m}$.

An analysis of shale blasts (Figure 4) showed that the mine design stemming length corresponded with the actual stemming length for five of the sixteen blasts. The average and maximum differences between the design and actual stemming lengths were $0.5 \mathrm{~m}$ and $2.0 \mathrm{~m}$, respectively.

The mine design stemming length was less than the ruleof-thumb stemming length in all blasts except blasts 1 and 16 . The average and maximum deviation from the rule-of-thumb stemming length values was $1.0 \mathrm{~m}$ and $2.3 \mathrm{~m}$ respectively. 


\section{The influence of stemming practice on ground vibration and air blast}

The actual stemming lengths used on the mining block for sandstone blasts were found to be less than the design stemming length for all 12 blasts investigated, as shown in Figure 5.

The actual stemming length values deviated from the design stemming length by an average of $3.4 \mathrm{~m}$. Blast number 10 was anomalous, with $10.0 \mathrm{~m}$ difference between the design and the actual stemming length. The design stemming length was greater than the rule-of-thumb stemming length for eight of the 12 blasts, with an average difference of $2.7 \mathrm{~m}$ and a maximum difference of $5.1 \mathrm{~m}$. In the sandstone blasts, hole diameters were designed at $250 \mathrm{~mm}$.

Sereme et al. (2019) provided the following possible reasons for the variation of actual stemming length from that recommended in the mine design:

i. The blasting team was given some flexibility to alter the blast design according to the block conditions after drilling

ii. Inaccurate drilling resulted in shorter or longer holes, and therefore in shorter or longer stemming lengths respectively

iii. Inaccuracy in charging of holes, with undercharging and overcharging resulting in longer and shorter stemming lengths respectively

iv. The presence of cracks may have affected the amount of explosives charged

v. The inaccuracy of the air-gap length

vi. Manual data entry of stemming lengths was inaccurate and prone to error

vii. Unverified data before filing

viii. Distortion of the correct measurement of holes due to uncleaned hole collars ix. Collapsed holes may have resulted in inaccurate stemming length when measured.

Non-technical reasons for the variation of actual stemming length from design stemming length may be attributed to noncompliance, hence poor stemming practice.

Due to the variance between the design stemming length and the rule-of-thumb (20D) stemming length, the researchers decided to perform further analyses by comparing how the design stemming length varied with the rule-of-thumb: $T=0.7 b$ to $1.2 b$ (Equation [2]). In Figure 6, upper and lower limit stemming length values were determined using Equation [2]. The majority of the coal blasts used a burden of $6.0 \mathrm{~m}$, which translates to upper and lower limit stemming length values of $7.2 \mathrm{~m}$ and $4.2 \mathrm{~m}$. The majority of the stemming length values were found to be less than the lower stemming length limit, as shown in Figure 6. Only one blast (blast 11) had a design stemming value that was within the rule-of-thumb bounds.

For interburden, the upper limit stemming length value of $9 \mathrm{~m}$ represents blasts with a burden of $7.5 \mathrm{~m}$ and the lowest limit value of $3.5 \mathrm{~m}$ corresponds to those blasts with a burden of $5.0 \mathrm{~m}$. The design stemming length was closer to the lower limit. and less than half of the design stemming length values fell within the rule-of-thumb bounds (Figure 7).

Design stemming length values for sandstone (Figure 8) blasts differed slightly from the trends shown by the coal and interburden blasts. All the sandstone blasts used a burden of $6.0 \mathrm{~m}$, which translates to an upper limit stemming length of $7.2 \mathrm{~m}$ and a lower bound of $4.2 \mathrm{~m}$. Of the 12 blasts analysed, five design stemming length values fell above the upper limit, two values were equal to the upper limit, and the rest were within the two limits.

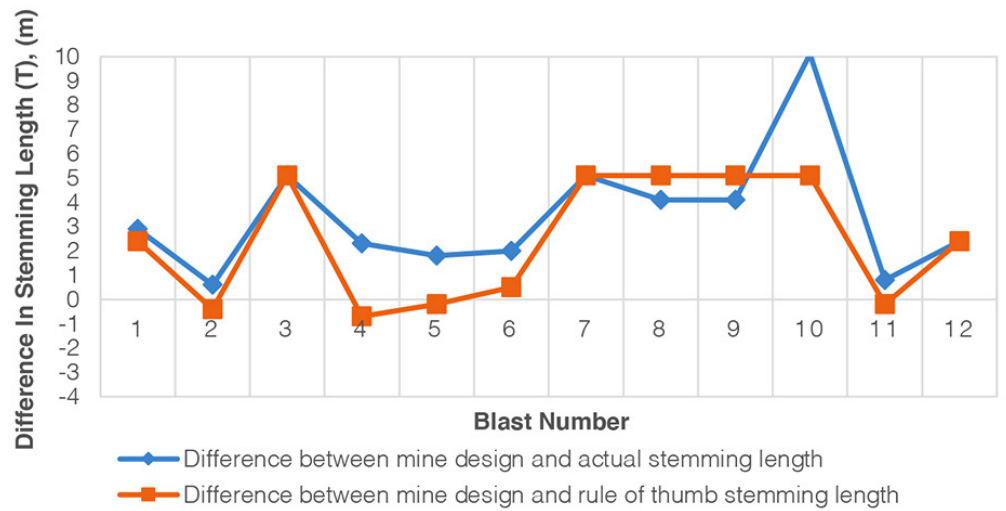

Figure 5-Stemming length variations for sandstone blasts

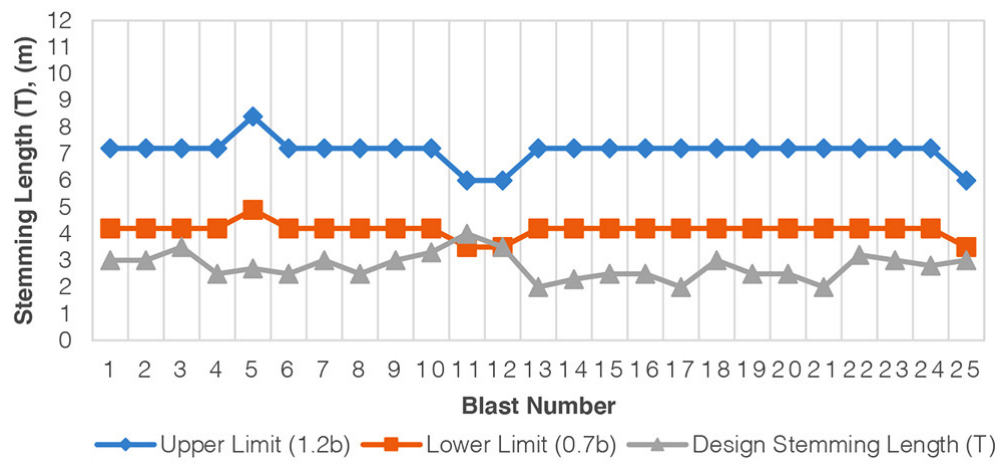

Figure 6-Design stemming length vs. the rule-of-thumb values for coal 


\section{The influence of stemming practice on ground vibration and air blast}

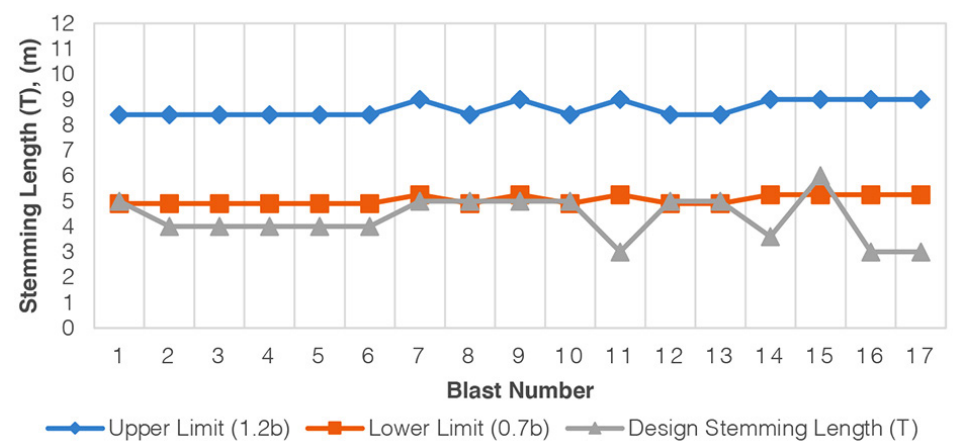

Figure 7-Stemming length vs. the rule-of-thumb values for interburden

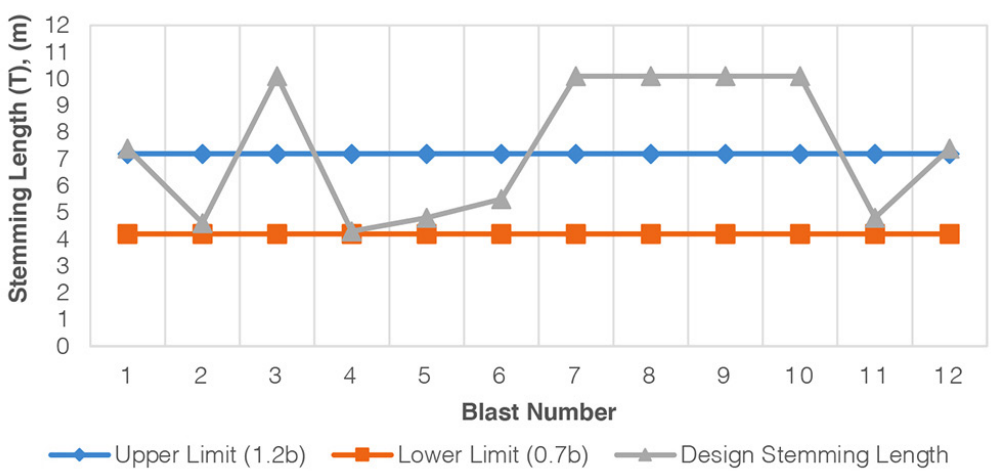

Figure 8-Stemming length vs. the rule-of-thumb values for sandstone

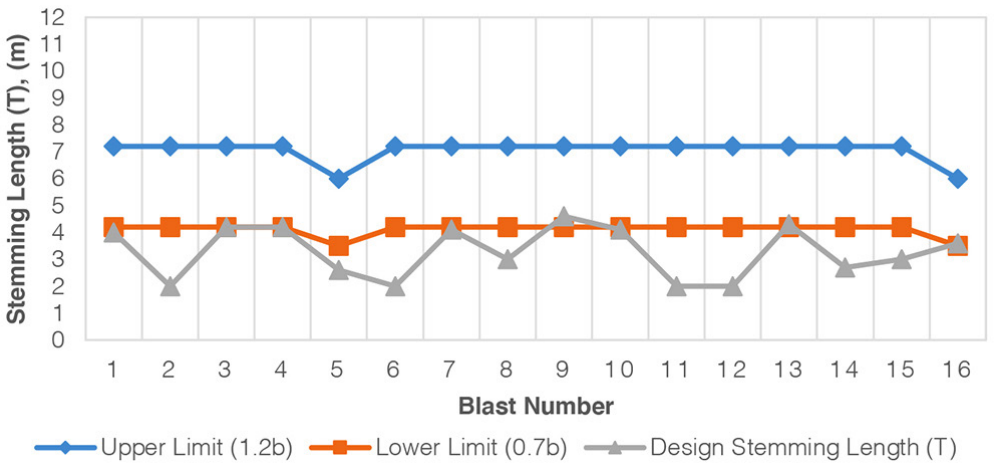

Figure 9-Stemming length vs. the rule-of-thumb values for shale

The majority of the values were below the lower limit of $4.2 \mathrm{~m}$ (which corresponds to a burden of $6 \mathrm{~m}$ ), and only one value was within the rule-of-thumb limit for stemming. It is also noteworthy that the design stemming lengths varied for most of the blasts.

The mine design stemming lengths for coal varied from the rule-of-thumb for the majority of the blasts. The differences between the rule-of-thumb stemming length and the design stemming length may be attributed to the site conditions, which necessitated modifications to the design. Fragmentation size requirements or the need to limit air blast and ground vibration may have been factors considered when designing the stemming length, resulting in a deviation from the rule-of-thumb stemming length.

\section{Stemming material}

An analysis of stemming material used for all the blasts revealed that the designed stemming material was used in practice on the mining block. The stemming materials used for the different blasts were aggregate, chrome slag, and drill chippings (for coal blasts). Compliance between the design and actual stemming material size with the rule-of-thumb for material size (Equation [3]) could not be ascertained due to the relevant data not being available. However, it should be emphasised that the rule-ofthumb serves as a guide only. Experience and mine-specific environmental conditions inform the choice of stemming material. Different stemming materials and stemming accessories had either been trialled by the mine or were trialled or being used in other operations with similar geology.

\section{Stemming-related parameters}

Burden and spacing

A comparison between the mine design and actual burden on 122 data-points showed that $78 \%$ of the burden values complied with the design (Figure 10). Since most of the burden values for different rock types were equal, and thus superimposed on each 


\section{The influence of stemming practice on ground vibration and air blast}

other, the number of data-points that are visible on the straight line of the graph is not a true reflection of compliance. Blasts with a design burden value of zero may have been one-row or presplit blasts. However, actual burden values greater than zero were recorded for some of these blasts. This may have been because of incorrect data capture.

Similarly, for spacing it was found that $22 \%$ of the actual spacing values did not comply with the mine design spacing. This type of non-compliance may have resulted from inaccurate manual capturing of data and/or a change in the design based on environmental conditions on the block. The spacing variation results are shown in Figure 11.

Since burden and spacing are a function of hole diameter, it is possible that a change in diameter resulted in the deviations of the actual burden and spacing from the design values. Further discussion on burden and spacing is provided in the qualitative analysis section.

\section{Hole depth analysis}

An analysis of actual hole depths was conducted to determine any variations from mine design hole depths. Figure 12 shows that there was some variation from designed hole depths, as indicated by the points which lie below or above the $\mathrm{x}=\mathrm{y}$ trendline. Of the 122 hole depth values, $78 \%$ did not correspond with the design hole depth. The average difference between the design and actual hole depth values was $1.6 \mathrm{~m}$, with a maximum difference of $13 \mathrm{~m}$.

Based on the graph, the general trend shows a close grouping of the points around the $\mathrm{x}=\mathrm{y}$ trendline. There are outliers; the difference between the design and actual hole depths was $10 \mathrm{~m}$ and $13 \mathrm{~m}$ for two blasts, shown within the dotted circle in Figure 12.

Hole depth is a function of bench height and subgrade drilling. The deviation between mine design and actual blasthole depths may possibly be attributed to the actual bench

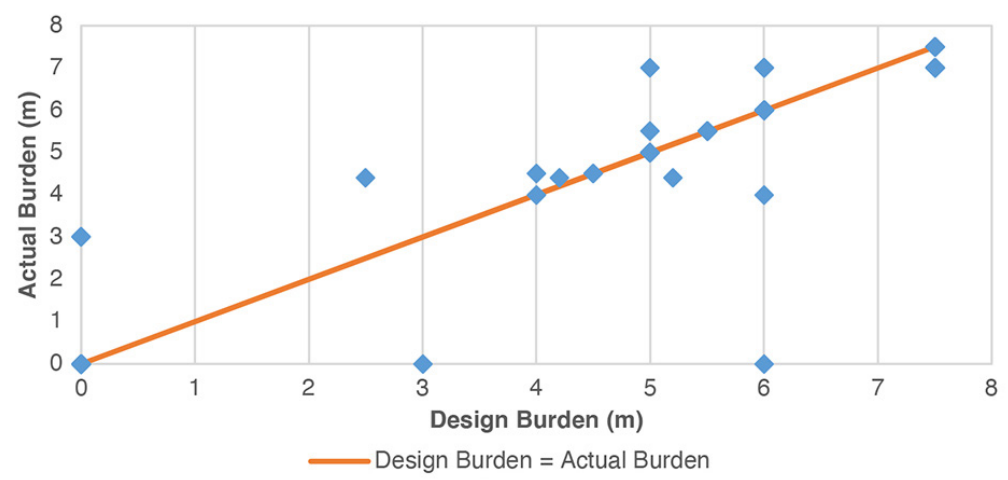

Figure 10-Variation between design and actual burden for all blasts

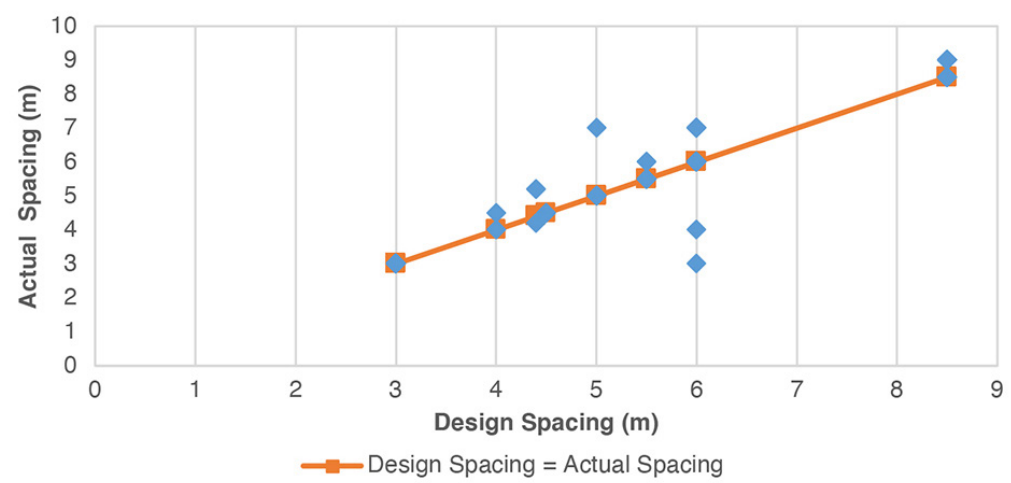

Figure 11-Variation between design and actual spacing for all blasts

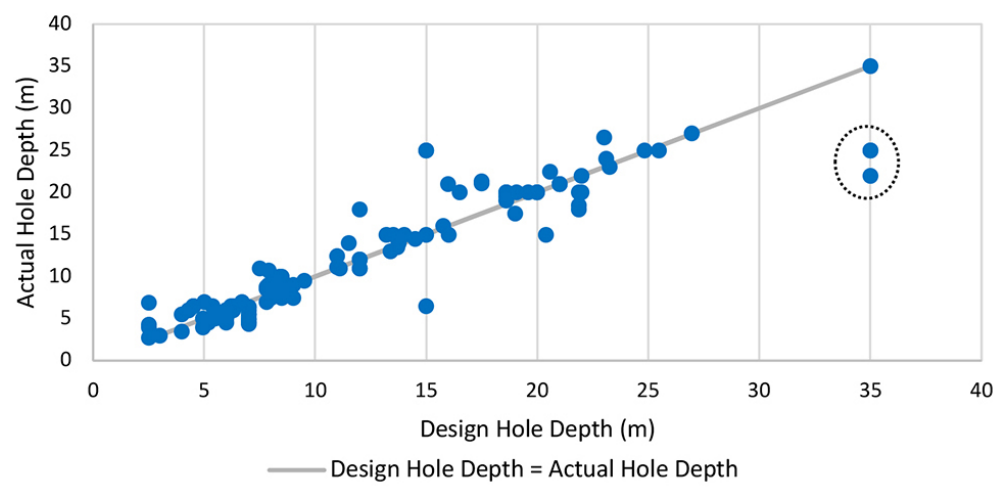

Figure 12-Variation between design and actual hole depths for all blasts 


\section{The influence of stemming practice on ground vibration and air blast}

height being less than or greater than the design bench height. Alternatively, some holes may have partially collapsed and become filled with drill chippings from the crest of the hole.

There are currently no guidelines to show the relationship between deviations from the design and the corresponding impacts on blasting. Hence, it is unclear whether the $1.6 \mathrm{~m}$ average difference in hole depth had a significant impact on blasting conditions. This statement also applies to the other parameters assessed, such as stemming length, burden, and spacing.

\section{Analysis of post-blast data in relation to stemming length}

As presented in Figure 13, the actual and design stemming lengths were compared and assessed against the air blast and ground vibration (PPV) results to determine if there was a correlation. The data for ground vibration and air blast recordings less than and greater than the threshold values are shown. The distribution of the seismograph results indicates that there is no correlation between non-compliant stemming lengths and ground vibration and air blast.

This is evident from the fact that some PPV and air blast results that exceeded the threshold plot on the $y=x$ line. Even though the actual stemming length for these blasts complied with the design stemming length, the ground vibration and air blast values exceeded the threshold values. Similarly, the two values at $7.4 \mathrm{~m}$ design stemming length (within the dotted circle), were below the PPV-air blast threshold, although the stemming length was less than designed.

There are, however, two exceptional cases for designed stemming lengths of $10.0 \mathrm{~m}$ in sandstone (within the dashed circle). Non-compliance of actual parameters with the design parameters such as stemming length and drill-hole depth may have resulted in inadequately confined or overconfined blastholes, possibly contributing to excessive air blast. Based on the majority of the results, as discussed above, there is insufficient evidence to suggest that poor stemming practice was the only cause of high PPVs and air blast (Sereme et al., 2019). However, poor stemming practices cannot be completely ruled out as a contributing factor to these adverse conditions. Further studies may be required to determine the actual causes of excessive ground vibration and air blast by timeously analysing data associated with blasts exceeding the thresholds. The results, however, will be highly dependent on the accuracy of data recorded by the drill-and-blast team.

\section{Qualitative analysis}

The following observations were made in relation to stemming practices, as reported by Sereme et al. (2019): i. The block was not well prepared, e.g. blast-hole collars were not cleaned

ii. Short holes that required re-drilling were charged without being re-drilled

iii. Burden and spacing were mostly inconsistent

iv. Blast-hole depths were mostly incorrect and no corrective measures were implemented

v. Trucks used for charging and stemming had difficulty manoeuvering around the holes due to the uneven and muddy nature of the floor, potentially covering already drilled holes

vi. Twining procedures were not followed at all times

vii. The explosive mobile manufacturing unit (MMU) operator had an assistant that informed him when the hole was pumped with sufficient explosives. This information was communicated by a whistle blow from the assistant. This manual operation has a high potential for human error and inconsistency

viii. Tying up of shock tubes (initiation systems) was a challenge due to misaligned holes.

Twining is a conventional method of ensuring that sufficient space is left in the hole for gassing of explosives, using a string to mark where stemming should start. In some blast-holes twining was not done, which increases the likelihood of incorrect stemming length. The positioning of blast-holes (burden and spacing) was done using a geographical positioning system (GPS), which is dependent on the network connection. It was observed that the GPS would often get disconnected from the network and blast-holes would be incorrectly positioned. Additionally, the qualitative analysis reaffirmed the quantitative analysis results by revealing that short holes were not re-drilled, burden and spacing were inconsistent, and incorrect blast-hole depths were not corrected.

Poor stemming practices cannot be attributed to a single non-compliant parameter, but may be caused by the knock-on effect of inconsistencies in any part of the process. For example, if blast-holes were drilled shorter or longer than designed, the stemming length would be affected. This emphasises the importance of adhering to the design parameters and, in the example above, ensuring that incorrectly drilled holes are redrilled to their correct depth if necessary. In cases where a blasthole is longer than designed, drill chippings should be used to refill it to the designed depth.

Although all activities in the mining cycle are important and interrelated, drilling is the backbone of all processes (Abbaspour et al., 2018; Messaoud, 2006). Non-compliant drilling

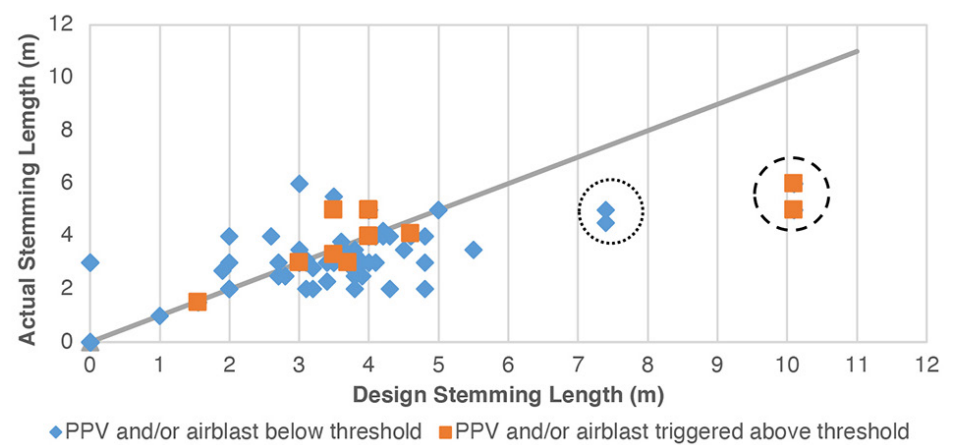

Figure 13-The relationship between stemming lengths and post-blast data 


\section{The influence of stemming practice on ground vibration and air blast}

practices directly result in non-compliant stemming practices, inconsistencies in charging and timing and, consequently, a nonconformant blast.

\section{Recommendations}

Based on the results of the study, the following recommendations are provided to improve stemming practices, which may ultimately contribute to improving the blast conditions at the mine.

i. Ensure the correct capturing of data and full completion of fields with the correct data format before submitting to the last level of authority for final sign-off

ii. Blast reports and charging control sheets should be thoroughly checked and verified by the various levels of authority before final sign-off

iii. The mine standards for quality control and quality assurance should be strictly followed after drilling of holes, after charging, gassing, and stemming

iv. Any deviations from the blasting plan parameters should be reported to the person of authority, who will then make an informed decision on appropriate mitigation measures

v. The responsible person of authority should update the blasting plan based on the deviations and feed back the information to the personnel on the block

vi. Investigate the development of digital entry and recording systems for capturing on-bench blasting parameters to reduce inefficiency and errors. Digital methods to record data may improve processes and ultimately result in better blasting

vii. Recording of blasting outcomes (e.g., fragmentation, loading times) could be correlated with (digitally recorded) blasting inputs and used as a tool to improve blast designs.

Improved information flow between personnel on the block and those at the mine offices may enhance the overall blast performance.

\section{Conclusion}

The stemming practices at a South African surface coal mine were investigated to determine if they had a significant influence on air blast and ground vibration. The investigation revealed that there is a need for digital entry and recording systems for capturing on-bench blasting parameters, as the current data recording and reporting systems are inefficient and prone to error. Improvements to blasting practices are possible through efficient and accurate data recording and reporting systems.

Non-compliance of actual parameters with the design parameters such as stemming lengths and drill-hole depths may have resulted in inadequately confined or overconfined blastholes, possibly contributing to excessive ground vibration and air blast. However, the quantitative analysis indicated that there was no direct correlation between stemming length and excessive air blast and ground vibration. Since blasting parameters are interrelated, we may conclude that poor stemming practice was not the sole cause of excessive air blast and ground vibration, but may have been a contributing factor to these adverse outcomes. It is therefore important that all blasting procedures (including stemming) are executed correctly and recorded accurately.
Finally, all blasting parameters should be assessed when air blast and ground vibration values exceed the threshold. This should be done as soon as such measurements are recorded, so that the fundamental cause may be determined and appropriate mitigation measures implemented.

\section{References}

Abbaspour, H., Drebenstedt, C., Badroddin, M., and Maghaminik, A. 2018. Optimized design of drilling and blasting operations in open pit mines under technical and economic uncertainties by system dynamic modelling. International Journal of Mining Science and Technology, vol. 28. pp. 839-848.

BajpAyee, T., Verakis, H., and LobB, T. 2004. An analysis and prevention of flyrock accidents in surface blasting operations. National Institute for Occupational Safety and Health, Washington, DC. https://www.cdc.gov/niosh/mining/ userfiles/works/pdfs/apfasbo.pdf

Banks, V.J., Palumbo-Roe, B., van Tonder, D.B., Davies, J., Fleming, C., and Chevrel, S. 2011. Conceptual models of Witbank Coalfield, South Africa. Natural Environment Research Council, Swindon, UK.107 pp. http://nora.nerc.ac.uk/ id/eprint/506746/1/EO-MINERS-D3.1-2\%20CSM\%20Witbank\%20FINAL_ signed_20120329.pdf

BME. 2018. Resources: Blasting Guide.: Bryanston, South Africa. http://demo.bme. co.za/downloads/send/2-brochures/2-blasting-guide [accessed 2 April 2018]

Boshoff, D. and WebBer-Youngman, R. 2011. Testing stemming performance, possible or not?. Journal of the Southern African Institute of Mining and Metallurgy, vol. 111, no. 12. pp. 871-874.

CevizcI, H. 2012. A newly developed plaster stemming method for blasting. Journal of the Southern African Institute of Mining and Metallurgy, vol. 112, no. 12. pp. 1071-1078.

DE GRAAF, W. 2013. Surface mining explosives. Explosives Engineering: University of Pretoria. pp. 3.10-3.19.

Karakus, D., Onur, A.H., KonaK, G., KöSE, H., and KizilcaAĞaçLi, M. 2003. Application of stemming plugs and a case study in a limestone quarry. Proceedings of the 18th International Mining Congress and Exhibition of Turkey (IMCET 2003). http://www.maden.org.tr/resimler/ekler/107931de60c5a7c_ek.pdf [accessed 6 May 2018].

Lusk, B. and Worsey, P. 2013. Explosives and blasting. SME Mining Engineering Handbook. Society for Mining, Metallurgy \& Exploration, Littleton, CO, pp. 443-459.

Messaoud, L. 2006. Drilling technology in mining industry. Acta Montanistica Slovaca, vol. 11. pp. 113-118.

Mohamed, E., Armaghani, D., and Motaghedi, H. 2013. The effect of geological structure and powder factor in flyrock accident, Masai, Johor, Malaysia. Electronic Journal of Geotechnical Engineering, vol. 18. pp. 5561-5572.

NEALE, A.M. 2010. Blast optimization at Kriel Colliery. Journal of the Southern African Institute of Mining and Metallurgy, vol. 110, no. 4. pp. 161-168.

NPS. 1999. Blast design. Handbook for the Transportation, and Use of Explosives. National Park Service, US Cepartment of the Interior, Washington, DC. https:// www.nps.gov/parkhistory/online_books/npsg/explosives/Chapter8.pdf [accessed 10 May 2018].

Patidar, P. 2017. Role of stemming in open cast mine. https://www.slideshare.net/ pankajpatidar15/role-of-stemming-in-open-cast-mine [accessed 17 May 2018].

Sereme, B., Mpofu, M., Roberts, D., Ngobese, S. and Lumbwe, T. 2019. Monitoring of blasting and determination of optimal stemming. Coaltech Research Association, Johannesburg. Unpublished report. 


\section{South African mining and metallurgy researchers ranked in the world's top 2\% scientists}

A recently published database [1] from Stanford University lists the top 2\% of science researchers in the world. Numerous South African scientists have found a place in the rankings for the sub-discipline of mining and metallurgy.

The research team, led by Dr John Ioannidis, created a database that includes the best scientists in the world, using standard citation indicators. The indicators took into account the number of citations, h-index, co-authorship adjusted hm-index, citations of papers in different authorship positions, and a composite indicator. The database categorized 160000 scientists in 22 scientific fields and 176 subfields.

The 21 South African scientists who featured in the Mining and Metallurgy ranking according to career-long citation impact are as follows:

\begin{tabular}{|l|l|c|c|}
\hline Name & Institution & No. of papers & Ranking \\
\hline Frank Crundwell & CM Solutions & 65 & 13 \\
\hline Sue Harrison & University of Cape Town & 156 & 38 \\
\hline Herman Potgieter & University of the Witwatersrand & 167 & 45 \\
\hline John Preston & Mintek & 51 & 55 \\
\hline Dick Stacey & University of the Witwatersrand & 98 & 108 \\
\hline Jochen Petersen & University of Cape Town & 84 & 119 \\
\hline Leon Lorenzen & Stellenbosch University & 87 & 123 \\
\hline Dee Bradshaw & University of Cape Town & 156 & 128 \\
\hline Michael Moys & University of the Witwatersrand & 89 & 135 \\
\hline Cyril O'Connor & University of Cape Town & 185 & 151 \\
\hline Kathy Sole & University of Pretoria & 42 & 159 \\
\hline Dave Deglon & University of Cape Town & 50 & 221 \\
\hline Jan Svoboda & De Beers Group & 32 & 225 \\
\hline Mariekie Gericke & Mintek & 30 & 272 \\
\hline Geoff Hansford & University of Cape Town & 54 & 274 \\
\hline Steven Bradshaw & Stellenbosch University & 100 & 286 \\
\hline Sehliselo Ndlovu & University of the Witwatersrand & 59 & 316 \\
\hline Salih Ramazan & AngloGold Ashanti Limited & 16 & 369 \\
\hline Jean-Paul Franzidis & University of Cape Town & 97 & 468 \\
\hline Victor Ross & Mintek & 22 & 524 \\
\hline Rob van Hille & University of Cape Town & 53 & 572 \\
\hline
\end{tabular}

1. BaAs, J., Boyack, K., and IoAnNidis, J. 2020. Data for 'Updated science-wide author databases of standardized citation indicators'. Mendeley Data, vol. 2. doi: 10.17632/btchxktzyw.2. https://data. mendeley.com/datasets/btchxktzyw/2 